\title{
Effective Utilization of Battery Banks in PV Based Novel Inverter Operated Induction Motor Drives
}

\author{
E.Hima bindu ${ }^{1}$, D.Krishna ${ }^{2}$ \\ ${ }^{1}$ Assistant Professor, Department of EEE, Geethanjali College of Engineering and Technology, Hyderabad, India ${ }^{2}$ Assistant \\ Professor, Department of EEE, Anurag Group of Institutions, Hyderabad, India
}

\author{
$\underline{{ }^{1} \text { himabindusrinivas2015@gmaill.com }{ }^{2} \text { krishnaeee@cvsr.ac.in }}$
}

\begin{abstract}
The three-phase squirrel cage induction motor is due to its many advantages, such as no maintenance, robust construction, etc., usually used for agricultural applications. PV induction motor drives are mainly used where no power is available. However, conventional two-level inverters that convert DC to AC do not provide a quality output. Therefore, this article describes an induction motor drive with a multilevel converter. In a home-based PV system, full use of battery packs is essential to reduce network dependency and improve reliability. To achieve this goal, it is important to keep the battery banks in an almost identical state of charge. This article proposes a technique for limiting battery banks by switching isolated panels. The selection of the isolated panels considers the irregularity of the position of the panels. In order to reduce network dependency and improve reliability, a switching model is developed for the photovoltaic system that considers the generation and load model. The proposed switching technique and model will be reviewed in the MATLAB / SIMULINK environment.
\end{abstract}

Keywords—PV panels, battery banks utilization, Multi-level inverters.

\section{Introduction}

It is increasingly laborious to meet the energy needs of the traditional generation. To meet the growing demand, distributed generation is the answer. Renewable energy systems are a source of clean energy. Among all renewable solar energy there is a lot. By reducing dependence on nonrenewable energy sources and reducing greenhouse gas emissions, solar energy ultimately contributes to energy security. With the increase in the price of the network per unit, solar energy can equal conventional coal fuels [1]. The disbursement of solar energy is instantly really ambitious with conventional coal electricity and it is expected to reach parity of the grid by 2020; Many countries are committed to reducing greenhouse gas emissions and generating at least $20 \%$ of their energy use from renewable sources by 2020 [1]. In this context, the generation of photovoltaic energy (PV) plays an important role, since it is a source that respects the environment. The only emissions associated with the generation of photovoltaic energy are those in the manufacture of its components. After installation, they generate electricity from solar radiation without exhaling greenhouse gases. They can also be equipped in places where there is no other treatment, such as: Roofs and deserts, they can generate power for remote locations where there is no electricity grid. The latest types of equipment are known as out of-network equipment and, on occasion, represent the most economical alternative to accommodate power in far-flung areas. Solar energy offers an economically workable option to connect to non-electrified areas. Some of the renewable energy technologies used as decentralized systems in rural areas are solar lighting systems, solar lanterns and solar lighting systems for the home, solar water heating systems, solar cookers.

Since India lies in the equatorial belt, the bright sun is expected in most areas on 250 to 350 days a year. The total radiant energy varies between 1600 and $2200 \mathrm{kWh} / \mathrm{m} 2$ [2]. An annual potential of 6000 million GWh of energy [2]. The Ministry of New and Renewable Energy is planning to install 10 major solar projects and one off-grid GW solar project by the end of 2017 [3].

On the other hand, two-level power electronic inverters are commonly used in photovoltaic drives and practices for converting DC to AC voltage [1]. The main problem of two level inverters, however, is the harmonic component that is very high in this inverter [2] - [3]. These problems are minimized by the use of power electronic multilevel inverters [5] - [7].Even supposing accustomed multilevel inverters have many advantages, they have certain disadvantages, such as the problem of balancing the neutral point voltage [8], the requirement for a larger statistics of capacitor banks [9]. ] and isolated DC power sources [10]. To diminish these disadvantages of typical multilevel inverters, plentiful multilevel inverter configurations have been proposed in the literature. In [11], an intriguing five-stage inverter configuration is proposed in which only two-level inverters are used to generate a five-level voltage waveform. In addition, this power inverter operates on a single DC source. By using this inverter configuration, therefore, all the problems mentioned in the conventional multi-stage inverters can be minimized. The main drawback of this above configuration, however, is that it requires six additional bidirectional 
switches that increase switching losses and line losses. In [12] - [13], another configuration of multilevel inverters is proposed, which minimizes the problems associated with traditional power multilevel inverters. However, this configuration covet more isolated DC sources, which increases the cost and complexity the circuit.

Therefore, it is important to determine the configuration of the drive that gives a better output to the drive output. In this sense, this article proposes an induction motor driven by a three-stage inverter. The proposed inverter configuration is simulated and the results are presented to show the validity of the proposed system.

\section{Purposed Multilevel Inverter Configuration}

A conventional method of extracting solar energy is to convert the consumer into a network or consumer in two stages [16]. The first step is the DC-DC conversion superseded by CC-CA as shown in fig.1. To implement the previous modeling of the photovoltaic generator, an MPPT algorithm, a battery and a converter are necessary. The detailed mathematical model of the photovoltaic arrays is presented in [7] - [8] considering several factors such as reverse saturation current, irradiance and temperature. Since the propagation of solar energy is $\mathrm{CC}$, a twostep conversion is used to feed the consumer or the network. The first step is to extract the maximum solar energy that MPPT can achieve. In [9] many MPPT configurations of OC, SC, slope scaling, incremental conductance methods, ANN based algorithms and fuzzy logic have been shown. The second step is the conversion from DC to AC. Multilevel inverters have the advantage of low harmonic distortion, low $\mathrm{dv} / \mathrm{dt}$ values, good electromagnetic compatibility (EMC) and low L and AC side filtering requirements compared to conventional inverters. Two levels [17]. It has been proposed that many topologies have a higher power quality, as indicated in [17]. To obtain a multilevel voltage waveform, capacitor banks or isolated DC voltages must provide small DC voltage steps. In [18], a three level multi configuration is performed using a cascaded bridge configuration. Using the same configuration, a three-level voltage waveform is obtained by dividing the total photovoltaic network into two equal parts, as shown in Fig.2. The switching sequence for generating a voltage waveform with three levels is shown in Table I. The power of the PV array decreases considerably with partial shading [10]. The use of bypass diodes or the parallel connection of a larger number of panels is

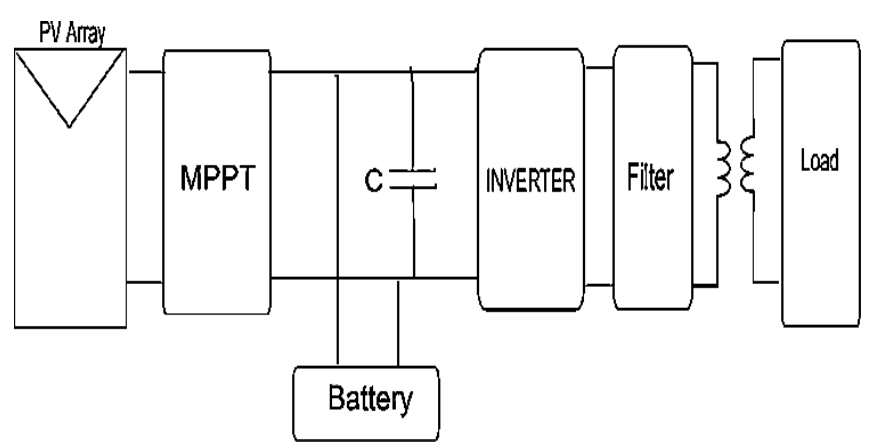

Fig.1: Dual two-level inverter with a single DC power supply.

an efficient way to reduce the power reduction due to partially uneven shading [10] [19]. The present moment work uses the $\mathrm{P} \& \mathrm{O}$ algorithm for the MPPT tracking and cascade inverter configuration. The main objective of this document is to improve reliability and reduce the dependency of the network by progressing a switching pattern that results in productive use of the energy stored in the battery banks. The use of a twostage topology in the conversion of direct current into alternating current is a conventional way to gain energy for a photovoltaic system. Conventional two-level power inverters are mainly used today to generate an AC voltage from a DC voltage. A two-level inverter has two output switching voltages $+\mathrm{Vdc} / 2$ and $-\mathrm{Vdc} / 2$ (the total voltage of the DC link is $\mathrm{Vdc}$ ). To engender an AC output voltage, a PWM (modulation signal is compared to the carrier wave) is used to change the branches of the power inverter to produce an output waveform that is similar to the modulation signal [20]. The advantage of PWM is that the dominant harmonics are multiples of the frequency modulation order $(\mathrm{jmf}+1)$, which leads to higher frequency harmonics and eventually reduces the filter requirements. The higher the frequency of the carrier, the higher the higher order harmonics and filter requirements [21]. Confide on the switching capacity of the IGBT / MOSFET, the frequency of the carrier is determined. The switching frequency for each device is determined by the turnoff characteristic, which is the aggregate of the door recovery time and the reverse recovery time (Tgr), (Trr) respectively. A disadvantage of the two-layer topology is a high $\mathrm{dv} / \mathrm{dt}$ value, a high EMI value and a higher filter requirement on the AC side (ie large values for $\mathrm{L}$ and $\mathrm{C}$ ). For some applications where space constraints (lower filtering requirements) and strict EMI / EMC, where two levels are not recommended, must be met [20] - [21]. 


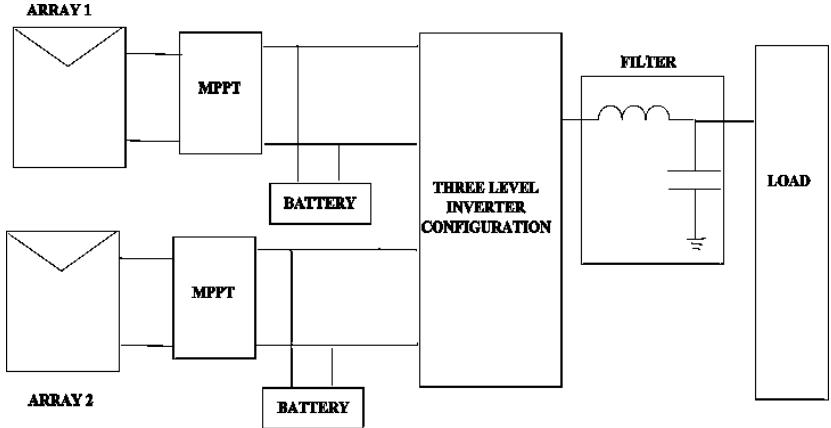

Fig 2. Solar Fig 3: Three phase three-level Cascade Bridge inverter

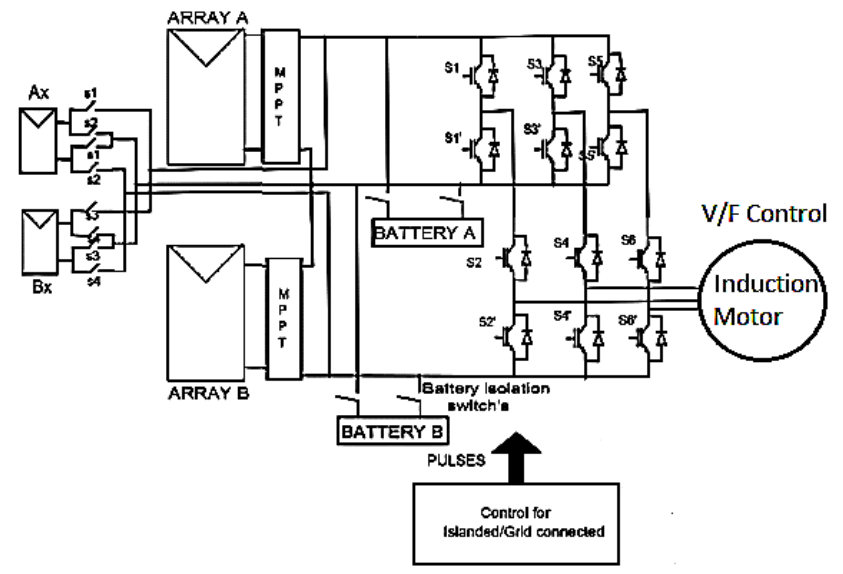

Fig 3: Three phase three-level Cascade Bridge inverter

Table 2A: Switching sequence to generate three-level voltage
waveform.

\section{Productive Implementation of stored energy in battery banks from sunset}

Once the battery banks are kept within the threshold, the consequent step would be to efficiently use the energy stored in the battery banks. Since sunset, demand has been met by battery banks or the connection to the network. The efficient use of stored energy can improve reliability and reduce dependency. To achieve these goals, a logic has been developed that allows switching between the connection mode of the island and the network. The switching model enables a more reliable power supply and reduces dependence on the network. The goal is achieved by working mainly in island mode, taking into account the structure of the requirement. Two more solar banks are called Ax and Bx. After isolating Ax, Bx, controlling $\mathrm{Ax}, \mathrm{Bx}$ is critically important depending on the conditions. Threshold selection is a compromise between minimizing the SOC difference and the switching frequency of the isolated panels. Below you will find possible incidents and the corresponding change action.

Case I : (SOC A - SOC B) < (-Threshold)

Connect Ax to Array A

Connect Bx to Array A

Case II : (SOC A - SOC B) > (+Threshold $)$
Connect Ax to Array B

Connect Bx to Array B

Case III : (-Threshold)<(+Threshold)

Connect Ax to Array A Connect Bx to Array

The proposed inverter is operated with induction motor drive and the simulation results are presented to show the validity of proposed inverter configuration with $\mathrm{V} / \mathrm{F}$ control in the entire linear modulation region. The block diagram which represents proposed inverter configuration with $\mathrm{V} / \mathrm{F}$ control in the entire linear modulation region is shown in Fig 3.

\section{Simulation Results}

The above topology is simulated and verified in the MATLAB / SIMULINK environment, as shown in Figure 4. If the favorable condition is equal to $+/-1$ (threshold - the total capacity of the battery), with which the battery banks and the following cases were simulated. Simulations were performed assuming that the SOC of the batteries was out of the favorable range. In all cases, an error is made in the ordinate axis and the time in seconds in the abscissa axis. The modulation and carrier signals are shown in FIG. The activation signals of each switch are shown in FIG. It is clear that the switches S1, S3 and S4 change only during half a cycle of a complete cycle. basic cycle. Only the switch $\mathrm{S} 2$ is conductive during the entire cycle. For some multistage inverters, however, all switches must be switched to a high frequency. This reduces switching losses compared to circuits that change completely.

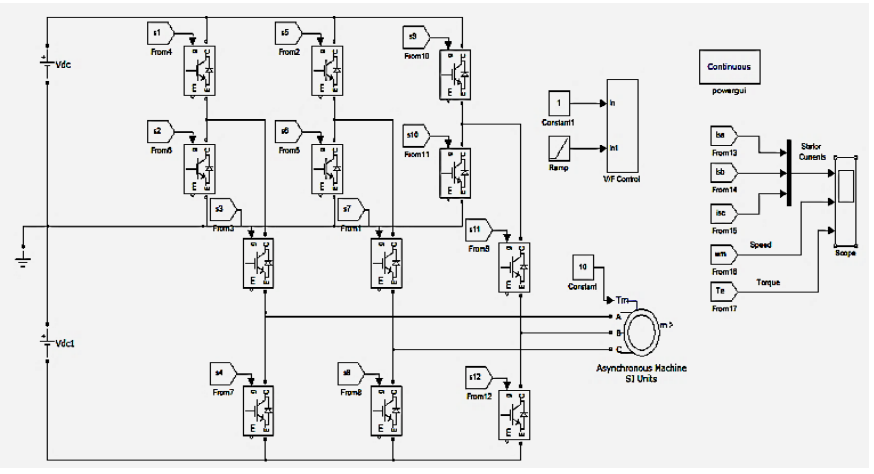

Fig. 4: Simulation circuit of proposed inverter Configuration

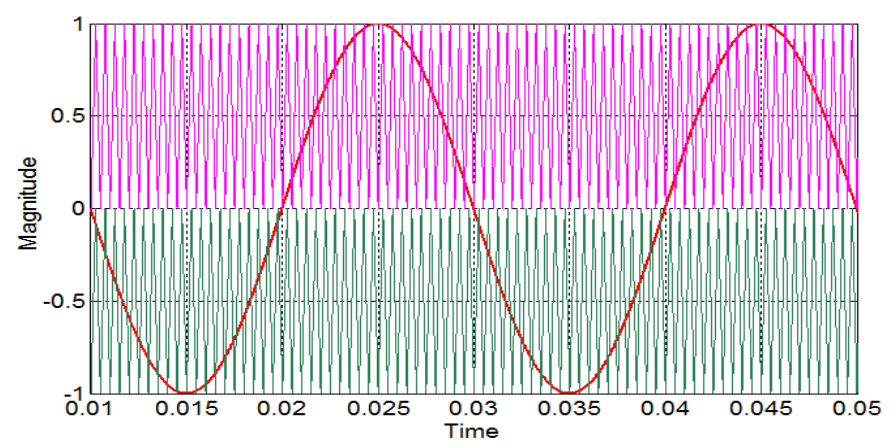

Fig 5: Modulating and carrier waves for proposed inverter Configuration 

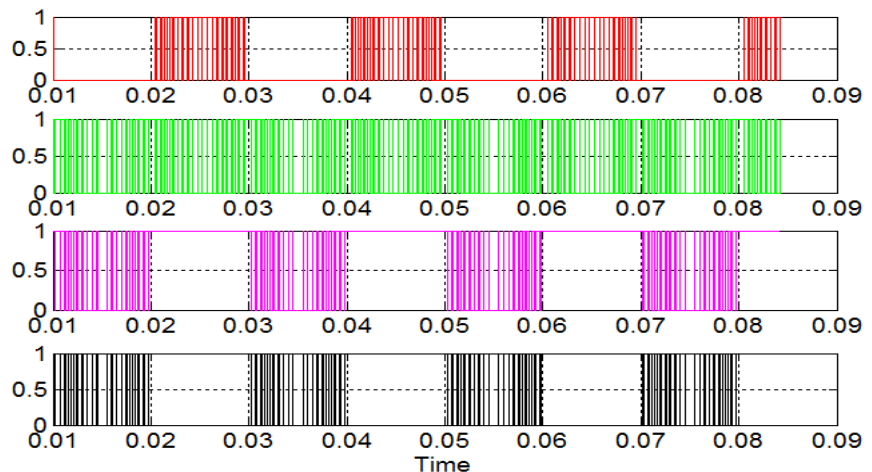

Fig 6: Gating Signals for proposed inverter Configuration (top one shows gating signal foe $\mathrm{S} 1$, second one shows for $\mathrm{S} 2$, third one is the gating signal of $\mathrm{S3}$ and the last one is the gating signal of S4)
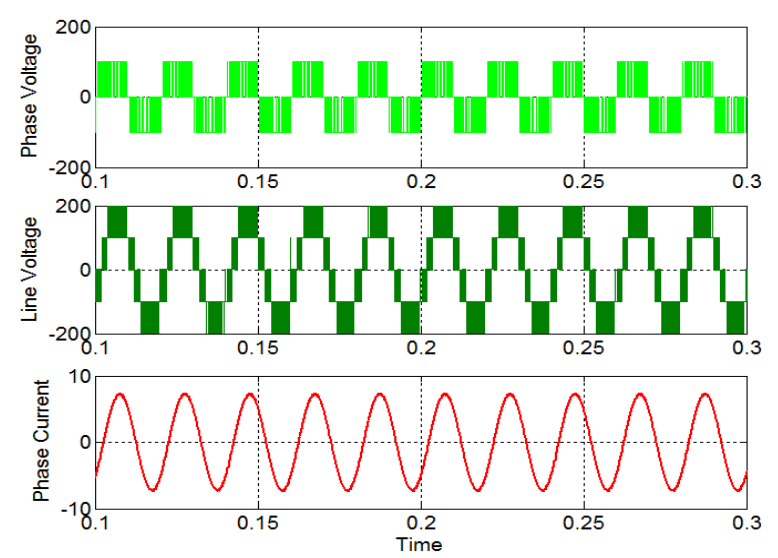

Fig 7: Phase voltage, line voltage and phase current

Fig. 7 shows the phase voltage, line voltage and phase current of a inverter fed induction motor drive. In this figure, phase voltage consists of three voltage levels and line voltage has more number of voltage levels. It is also clear from the figure that, it pure sinusoidal output current. The stator currents and speed and torque are shown in Fig 8.
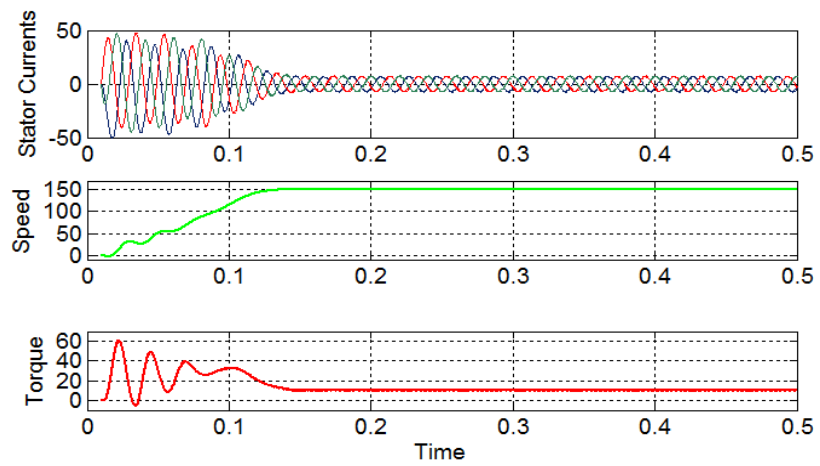

Fig 8: Three phase stator currents, speed and torque of induction motor drive

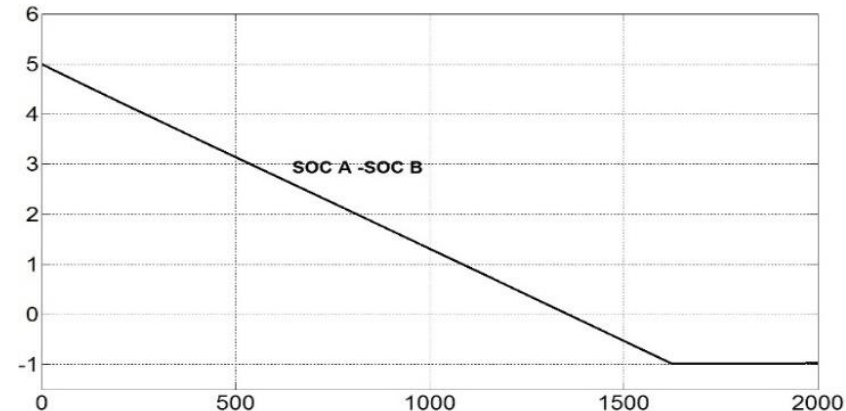

Fig 9: Error signal or Difference in SOC's of two battery banks in case 1

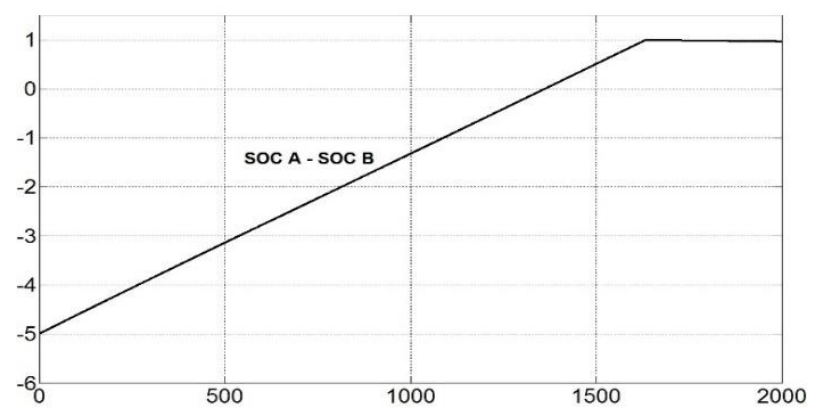

Fig 10: Error signal or Difference in SOC's of two battery banks in case 2

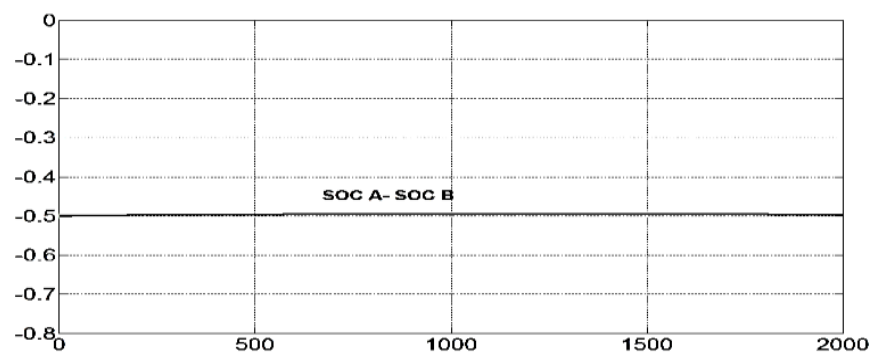

Fig 11: Error signal or Difference in SOC's of two battery banks in case 3

Initially "Battery bank A" is leading the "Battery bank B and it is outside the threshold band. Interrelated switching action was taken by control switches and error is deprecated as shown in fig. 9. When the "Battery bank B" is leading the "Battery bank A" and it is outside the threshold band. Corresponding switching action was taken by control switches and error is minimized as shown in above fig. 10 . When both battery banks are equal state of charge then there is no requirement of charging batteries and it is shown in Fig.11.

\section{Conclusion:}

A photovoltaic system has been proposed that allows the complete use of the battery packs by minimizing the difference in the discharge levels of the battery packs. The selection of insulated panels has been described, taking into account the worst-case state of charge variation from the upper and lower battery groups. A control policy has been developed to change the selected isolated areas according to the current SOC. In addition, switching between island mode and network mode uses the energy stored in groups of batteries to improve reliability and reduce network dependency. To 
achieve this goal, the logic has been developed to switch between island connection mode and network connection mode, taking into account the generation and load model. By using the stored energy efficiently, the user can spend more time in isolated mode, improving reliability and reducing network dependency. By using fewer switches, the proposed system can utilize two groups of batteries within the desired threshold, allowing full use of the battery banks. Although the proposed technique has been implemented in a three-stage inverter, it can be elongated to multi-stage power inverters with more than two battery groups.

\section{References:}

[1]. Carraro M. and Zigliotto M., "Automatic Parameter Identification of Inverter-Fed Induction Motors at Standstill," IEEE Trans. Ind. Electron, vol.61, no.9, pp.46054613, Sept. 2014.

[2]. K. Nallamekala, "Harmonic Cancellation Technique of Four Pole Induction Motor Drive by Using Phase Shifted Carrier Space Vector PWM Technique", Majlesi Journal of Electrical Engineering, vol. 12, no. 2, pp. 21-28, Jan. 2018.

[3]. Araujo R.d.S., Rodrigues R.d.A., de Paula H., Filho, B.J.C., Baccarini L.M.R. and Rocha, A.V., "Premature Wear and Recurring Bearing Failures in an Inverter-Driven Induction Motor-Part II: The Proposed Solution," IEEE Trans. Ind. Appl., vol.51, no.1, pp.92,100, Jan.-Feb. 2015.

[4]. Nallamekala, K.K.; Sivakumar, K., "A Fault-Tolerant Dual Three-Level Inverter Configuration for Multipole Induction Motor Drive With Reduced Torque Ripple," in Industrial Electronics, IEEE Transactions on , vol.63, no.3, pp.1450-1457, March 2016.

[5]. K. Nallamekala, S. Dandabatthina and V. K. Tella, "A novel fault tolerant 21-level inverter configuration for PV applications," 2017 International Conference on Circuit, Power and Computing Technologies (ICCPCT), Kollam, 2017, pp. 1-7.

[6]. Yuhei Okazaki, Makoto Hagiwara and Hirofumi Akagi,"A Speed-Sensorless Start-Up Method of an Induction Motor Driven by a Modular Multilevel Cascade Inverter (MMCI-DSCC)", IEEE Trans. Ind. Appl., vol. 50, no. 4, pp. 2671-2680, Jul./Aug. 2014.

[7]. Nallamekala, K.K.; Kalyan U, M.; Sivakumar, K., "Harmonic reduction technique with a five-level inverter for four pole induction motor drive," in Proc. of IEEE IFEEC, pp.482-487, 3-6 Nov. 2013.
[8]. Mohan M., Renge and Hiralal M. Suryawanshi, "FiveLevel Diode clamped Inverter to eliminate Common Mode Voltage and Reduced dv/dt in Medium voltage rating Induction Motor Drives," IEEE Trans. Power Electron., vol. 23, no. 4, pp. 1598-1607, Jul. 2008.

[9]. Nuntawat Thitichaiworakorn, Makoto Hagiwara and Hirofumi Akagi, "Experimental Verification of a Modular Multilevel Cascade Inverter Based on Double-Star Bridge Cells", IEEE Trans. Ind. Appl., vol. 50, no. 1, pp. 509-519, Jan./Feb. 2014.

[10]. K. K. Nallamekala, B.S. Umesh and K. Sivakumar, "A five-level inverter topology for four pole induction motor drive using four two-level inverters and two isolated DC sources," 2014 IEEE International Conference on Power Electronics, Drives and Energy Systems (PEDES), Mumbai, 2014, pp. 1-5.

[11]. Jain S., T. A.K., Karampuri R. and Somasekhar V.T., "A Single-Stage PhotoVoltaic System for a Dual-Inverter fed Open-End Winding Induction Motor Drive for Pumping Applications", IEEE Trans. Power Electron., doi: 10.1109/TPEL.2014.2365516.

[12]. Baiju M.R., and Shiny G., "Fractal-based low computation space phasor generation scheme for a four-level inverter using an open-end winding induction motor", IET Electric Power Appl., vol.6, no.9, pp.652-660, Nov. 2012.

[13]. K. Nallamekala, "Harmonic Cancellation Technique of Four Pole Induction Motor Drive by Using Phase Shifted Carrier Space Vector PWM Technique", Majlesi Journal of Electrical Engineering, vol. 12, no. 2, pp. 21-28, Jan. 2018.

[14] M. Chen and D. Sun, "A Unified Space Vector Pulse Width Modulation for Dual Two-level Inverter System," in IEEE Transactions on Power Electronics, vol. 32, no. 2, pp. 889-893, Feb. 2017.

[15] .Z. Shen, D. Jiang, J. Chen and R. Qu, "A novel zerosequence current elimination PWM scheme for an open-end winding motor drive with dual two-level inverter," 2018 IEEE Applied Power Electronics Conference and Exposition (APEC), San Antonio, TX, 2018, pp. 1679-1686.

[16]. J.-S. Kim and S.-K. Sul, “A novel voltage modulation technique of the space vector PWM," in Proc. IPEC Conf., 1995, pp. 742-747.

[17]. N., K.K. and Sivakumar, K., "A Quad Two-Level Inverter Configuration for Four Pole Induction Motor Drive with Single DC Link," IEEE Trans. Ind. Electron., doi: 10.1109/TIE.2014.2327577. 